\title{
Maritial Crisis in the Nigerian Society: Causes, Consequences and Management Strategies
}

\section{Amadi Ugochukwu P N}

\author{
Micahael Okpara University of Agriculture, Umudike - Nigeria
}

Amadi Felicia N C

Federal College of Education (Technical), Umunze - Nigeria

Doi:10.5901/mjss.2014.v5n26p133

\begin{abstract}
This study was informed by the rising profile of broken homes in the Nigerian society of contemporary times as many Nigerian homes today are riddled with marital crises. The investigation was designed as opinion survey using a structured questionnaire rated on a 4-point scale. Three research questions and four null hypotheses guided the investigation, and generated data was analyzed using descriptive statistics of the mean and standard deviation, while the hypotheses were subject to the t-test statistic. Findings indicated that emergence of crises in marital homes is occasioned by a lot of factors including incompatibility in social and sexual life, lack of marital confidence, third-party syndrome, economic disquiets, to mention a few. Consequences of marital crises were identified to include; poor mental, emotional and physical health of couples and their children, physical abuse and threat to life of partners, escalation of social vices and crimes such as drug abuse, kidnapping, prostitution, deschooling of children of crises-ridden and broken homes. Recommended management strategies include pre-marriage orientation, seminars, workshops and counseling. The education system was identified as a potent medium for reducing the threat of marital crises sequel to which a curriculum approach was recommended, proposing the integration of pre-marriage courses and family living into the Basic Education Programme.
\end{abstract}

\section{Introduction}

The family is a fundamental social institution occurring in all societies, although its particular forms differ substantially from place to place. Stark (1987) identifies four primary functions of the family to include the following: sexual relationships, economic cooperation among members, reproduction and, the educational function - socialization of children.

Again, the family is defined as the basic unit of the society. In other words, the family provides the bricks for the building of the society. The society therefore is an aggregate of the families (The Holy Bible Genesis 2:18- 22).

At any given time in human history, a family comes into existence each time a marriage is successfully contracted. This claim is corroborated from the biblical account of God's creation of Adam and Eve whom He accommodated in the 'Garden of Eden' and charged with the responsibility of procreating to fill the earth. Again, St. Paul in the Holy Bible says that for the reason of marriage 'a man will leave his parents and cling unto his wife and they both will become one husband and wife ${ }^{1}$.

Marriage is a covenant relationship between male and female spouses. The covenant nature of marriage provides a strong foundation and secure framework for spouses' commitment to each other. Covenant defines the marital responsibilities - of husband and wife toward nurturing and protecting their marriage. The couple is expected by their covenant to work hard to reach the level of relationship which protects the marriage from both internal and external negative forces (Zhekwo, 2009).

With the arrival of children, the family keeps expanding. This is true within the African context where marriage is seen basically as a process of procreation. A good marriage guarantees a peaceful and joyful atmosphere in the home, which is most suitable for bringing up healthy and happy children. Research has shown that children who grow up in such environments are more likely to excel in school and in all other aspects of life including their own marital life (Okon, 2010). Experiences over the years have shown that at times a once blissful marital union turns sour. But before the table turned, the couples believed they were soul-mates as indicated in the way they worked together, walking hand-in-hand, exchanging pleasantries. Each partner then was a true friend, a confidant with good sense of humour ever willing to offer a helping hand to the other. 
But as the table turns, couple soon realizes they no longer share the closeness feeling rather as strange bed fellows, speaking to each other only when it becomes absolutely necessary and inevitable. At this stage, some couples who are sensitive could start to wonder how they managed to get where the presently are - conflict has set in and of course if not properly handled at this stage may lead to crisis and eventual collapse of the marriage structure.

Every marriage is constantly under the influence of some external and internal pressures, a condition that it is somewhat inevitable that every marital union faces the dynamics of marital crisis. Crises are therefore a common feature in every union or association of two or more persons and marriage is not immune to this. If it is not so, why then do couples fright and argue? Why can't they just enjoy lasting peace? Didn't they get married to have a greater life together than in a single (unmarried) state? These are questions on issues that confirm that conflicts in marital unions might not be unusual and abnormal after all. What might be of serious concern would be why such minor misunderstandings that characterize a healthy union of people often snowballs into a conflict point. People will always have differences of opinions and expectations, what we do with these dissimilar viewpoints are what will characterize our lives and marriages. Great marriages are those that have learned how to utilize these variant shades of opinions and views so that they as a couple can grow.

We need to realize that conflicts are more than the simple difference of opinion or approach. Conflicts are the ways couples poorly carryout the expression of their varying view - points. Spouses can get quite mean and cruel at times even at the slightest provocation. On the other hand, we can see that those crises also serve as opportunities to draw us closer to God and closer to our spouses. Proverbs 20:3 says "keeping away from strife is an honour for a man, but any fool will quarrel", this simply implies that crisis must not always lead to conflicts for in the words of Buckwell (2010) God has given each of us a door of opportunity in which we can refuse to step into conflict.

As the Holy Bible realistically acknowledges that those who marry are likely to have pains and grief (1 Corinthians 7: 28), no couple or marriage is immune to such inherent problems. What starts out as a relationship of great joy and promise can become the most frustrating and painful endeavour in a person's life time. Eventually, all couples experience a significant crisis that can threaten their emotional safety and at times even the future of their marriages.

The family reckoned as the oldest human institution is today in trouble. The frightening spread in teenage drug abuse and immorality, the modern plague of divorce and faulty violence, the geometric increase in the number of singleparent families and other serious problems make one to wonder if the family life will survive the $21^{\text {st }}$ century and if it is still possible for a family to be a stable, nurturing environment for its members. This could only be possible if family members come to understand the real secrete of family happiness (Watch Tower Bible and Tract society of Pennsylvania, 1996).

It is against the foregoing background that this study set out to investigate marital crises in the Nigeria society with a .view to determining their causes and effects so as to recommend strategies for proper management. Dealing with martial crises is always difficult and solutions do not come easy. A saying in business that "anyone making no mistakes is not doing anything" can well apply to all other human endeavours, which include marriage that would always experience common crisis and the level of response of the couple is a decisive parameter for the success or failure of such marriages.

In the words of Scobie (2009), the union between man and woman is a reflection of the image of God in us and can only be sustained through lifelong devotion. That is to say that any libertine behaviour is against the covenant itself.

\section{Causes and Consequences of Marital Crises}

It is unrealistic to expect a marriage to be problem-free. After all, even well -matched marriage, partners are not perfectly compatible hence difficulties of some sort are inevitable. Just as rust can corrode metal under a coat of paint, a number of factors can eat away at an apparently successful marriage (Awake, 2008).

Crises in homes or families do not just go unnoticed because wherever a crisis exists in the family, the atmosphere of such a family is everything but congenial, the atmosphere changes - a once happy, family would become chaotic and characterized further by teenage rebellion, child abuse, spousal violence, alcoholism, extra-marital affairs, gambling, drug addiction and in extreme cases health problems such as hypertension, heart-attack /failure and emotional breakdown follow as consequences. Some affected couple becomes addicted to their work yet others develop varying degrees of mental disorder including psychotic and psychopathological health conditions.

Keeping away from strife is normal and proper. But the question remains 'whether we should or can handle these crises in order to avoid them developing into conflicts'. Wasson (2010) while, counseling on 'How to keep hope alive during marriage crises' maintains that because of human desires, we will still have misunderstandings, differing opinions, selfish times, lazy moments etc.

Though in marriage such differences are presumed to melt away but as a couple, it is not always easy to give up 
that uniqueness or individualism in our everyday life. This is notably so because both husband: and wife have different habits, were nurtured from different socio-economic and psychological backgrounds, with different biological parentage hence different genetic makeup, different educational background, different personalities and different emotional scars (DeHaans, 1986)

Problems and attitudes regarding material things can divide families in many ways. Divisions may develop when marriage mates work securely and cultivate a "my money-your money" attitude (The Watch Bible and Tract Society, 1996). When a marriage starts to witness resentment, constant arguing, infidelity, bitter speech, hostile reactions to simple questions or minor mistakes, mistrust, bickering to mention a few, that marriage is prone to crisis in no distant time. A sudden loss of interest in normal family activities, a sudden need to leave home early to go to work and keeping of late hours after work, a sudden inability to please one's spouse, sudden and unexplained trips out of town are all symptomatic of a crisis-prone marital union (Amadi, 2009).

\section{Causes of Marital Crises}

Marital crises could originate from different sources some of which could be psychological and / or psychosomatic in nature. Tobin (2004) attesting to the above claim retorts that more and more marriages run into crisis and eventually pack up because one partner has a borderline personality disorder such as narcissist, antisocial, psychopathic personality disorders. These sort of people are abusers by nature where as some are even unaware or unconscious of their near helpless conditions.

\subsection{Social Incompatibility of Marriage Partners.}

There is no doubt that some marriages have absolutely no foundation or basis for being contracted at the first instance. This is so because the pair is socially incompatible and may only manage to get along for a short while before signs of incompatibility would start to manifest. It would then be discovered that the couple are strange bed fellows - socially, religiously and ideologically. Crises are bound to ensue in a situation where a marriage partner sets high and unrealistic standards in the home. The fallibility of man is unquestionable and as such it is not possible that such idealistic standards are realized. This is capable of degenerating into crisis in the home. Many married people become disillusioned when they discover that their union is not all they had expected and that their spouse is not quite what they had envisioned him/her to be (Awake, 2008). Additionally, some couples unrealistically expect to get more out of marriage than they put into it.

\subsection{Sexual Incompatibility}

Poor sexual-satisfaction on the part of a marital partner may spice up crisis in the union which not properly-and timely detected and managed could lead to extramarital sexual affairs - a situation that if on its own leads to disaffection and loss of trust.

\subsection{Extreme Sexual Orientation}

Extreme sexual orientation of one of a marriage partner is capable of endangering a marital union. Such orientations like homosexuality, lesbianism, bestiality, sodomy, oral sex, excessive sexual appetite especially when the other partner is at the other extreme of the scale can generate crisis in the homes. Most of the time, such extreme sexual behaviours or orientations are discovered rather too late or midway into the marriage that it becomes very difficult to pull out of the engagement. And when once a partner cannot get along crisis ensues.

\subsection{Extended Family Affairs/Issues.}

Some once upon -a-time happy couples have had their marriages rocked for their inability to properly manage extended family issues. In most cases, women find it difficult to accommodate relations of the husband (especially mothers and sisters - in-law) and vice versa on the part of some husbands, a situation most marriage partners may find difficult to accommodate. Some men/women often quarrel with spouses whose interests are only on the betterment of their own relations. 


\subsection{Lack of Mutual Respect between Partners}

Mutual respect for one's spouse is critical for marital union sustenance and lack of it is a crisis factor capable of rocking even the strongest marital foundation of hitherto blissful homes. The Holy Bible admonishes couples thus: wives respect your husband who in turn should love their wives as they would their own body. One can quickly assume that each of the above mentioned conditions is a sine qua non for the other since a husband might find it difficult to continue to love a wife who doesn't respect him or his authority; neither would a wife respect the husband who does not love her. Respect and love are reciprocal variables in every marital union and as such, a spouse owes it an obligation to respect and love his/her marriage partner, failure which fans the embers of marital discord and discontent.

\subsection{Dishonesty and Moral Decadence}

Dishonest behaviour coupled with moral decadence in the family can generate crisis in the home. A situation where a couple cannot tell each other simple truth is not healthy for the union. Once such morality gap is discovered in any of the spouses, mistrust sets in and confidence gradually gets eroded with crisis eventually taking over the home front. Poor morality or decadent moral culture may unwittingly be imbibed by the children of such a family in which case the entire family fabric weakens due largely to an atmosphere of mutual mistrust that eventually envelops it. (Buckwell, 2010)

\subsection{Negligent Behaviour of Spouses}

Negligent behaviour on the part of marital partners is a critical crisis factor. In taking marital vows, a couple normally would promise to oblige the partner of his/her responsibility towards him/her, while avoiding indulgences that could mar their union. But experience has shown that soon after, some marriages collapsed on the strength of negligence of such avowed obligations. On this, a partner would start to feel cheated thus giving opportunity for tension to build up.

\subsection{Poor Marital Communication}

A factor that has occupied central position in all discourse concerning successful marriage is 'marital communication ${ }^{1}$ (Edger, 1996). Inability of spouses to communication effectively with each other is very unhealthy to the union. Effective marital communication entails that couples discuss issues, respond to questions, call for explanations and accept same timely (when given), as any delay may send out a wrong signal which a partner is bound to interpret same way. Effective marital communication can in fact assuage many other marital disquiets before they could degenerate into crisis situations. Put differently, poor marital communication has been blamed for some other marital problems that have even culminated into divorce or separation of spouses. Purposeful open dialogue between couples often tends to be overtaken by incessant arguments about anything, everything, and nothing; misinterpretation generates misunderstandings; verbal attacks are countered by keeping silence especially on the husband's side (Awake, 2008)

\subsection{Unwholesome Social Behaviour}

Bickering, unnecessary criticisms, gossip or what may simple be tagged nagging has rocked some good families. It is not an over statement that majority of the women take to nagging instead of politely confronting their husbands with issues. Most men in turn do not take kindly to such threats and would go a long way to crushing such tendencies. This case of attack and counter attack is crisis prone, as no reasonable man would want his authority as the family head be usurped.

\section{Consequences of Marital Crises}

Marital crises may have had some deleterious consequences on couples, their children and the society at large. Available literature reveal as follows:

\subsection{Social Vices and Crimes}

Social vices and crimes may become the order of the day as delinquent children from crisis-ridden or broken homes ultimately graduate into irresponsible adult population. The adolescence is a stage at which human beings are highly emotionally unbalanced, character formation not yet stabilized and as such people can always tilt to either side of the 
scale at the slightest pressure. This is the singular reason why robbery gangs kidnap and assassination squads, and prostitution are mostly populated by people in their adolescence and early adulthood. Living with their parents did not offer them the opportunity to develop as good citizens with good scales of conscience.

\section{Management of Marital Crises}

Couples who are going through a marriage crisis are often tempted to brood over the days when they still saw each other through the blissful eyes of love. At the earlier stages of all marriages, partners are always caught in a whirlwind of passionate emotions thus making them incapable of finding any fault in each other. This is because this highly idealistic phase of marriage temporarily obscures the truth that a marriage is made up of two separate people with differing perspectives on life (www.savemymarriagetoday.com). But sooner or later, such partners will eventually come face to face with the realities of their differences and the experience can be very traumatic for some spouses; some are downright disgusted by suddenly realizing that their marriage is in fact far from the ideal perfect.

That a marriage which started out so wonderfully well could end up in such a woeful state is an experience that has kept many a disillusioned couple from denying the existence of marriage crisis starring them in the face. This situation often compels some marital partners to opt to reminisce a trouble-free past, wishing things could go back to what they were before. But notably, this kind of wishful thinking is damaging in the long run because one need to acknowledge all the aspects of the relationship, be it good or bad. However, dealing with the negative tendencies has to be constructive (www.saygmymama.qetoday.com). Affected couple should rather consider the root causes behind their present woes and address them accordingly. It must however be appreciated that relationship problems are not same as say a problem with your car or laptop which requires a straight-forward solution. Marriage is a complex socio-psychological relationship and consequently, a marital crisis is anything but simple. Consequently taking the first step to deal with it is often the hardest. However, it must be done; otherwise, refusing to acknowledge and understand it is counterproductive.

\section{Study Objectives:}

In this study the following objectives were addressed:

1. Determine caused of marital crises in the Nigerian society

2. Determine possible consequences of marital crises

3. Determine strategies for effective management of marital crises in the Nigerian society.

\section{Research Questions:}

The following Research Questions guided the study:

1. What are the causes of marital crises in the Nigerian society?

2. What are the consequences of marital crises on the Nigerian society?

3. What are the strategies for effective management of marital crises in Nigeria?

\section{Hypotheses}

The following null hypotheses tested at .05 confidence level guided the study:

1. There is no statistically significant mean pinion difference between the Clergy/marriage counsellors, Intact Married Couples (IMC) and Single Parent Families (SPF) causes of marital crises in the Nigerian society.

2. There is no statistically significant mean difference in the opinions of male and female respondents on the causes of marital crises in the Nigerian society.

3. There is no statistically significant mean pinion difference between the Clergy/Marriage counsellors, Intact Married Couples (IMC) and Single Parent Families (SPF) consequences of marital crises in the Nigerian society.

4. There is no statistically significant mean difference between the opinions of male and female respondents on the consequences of marital crises in the Nigerian society

\section{Methodology}

The study was designed as opinion survey as it sought the views of the various categories of respondents on the problem 
being studied.

\subsection{Scope of the Study}

The study which merely sought the views of the respondents on causes, consequences of marital crises and management strategies was geographically limited to three South-eastern states of Nigeria namely; Abia, Anambra and Imo. In specific terms two (2) towns (1 urban and 1 rural) were selected from each state thus giving a total of six (6) sample towns from which respondents were drawn. The towns were as follows:

Table 1: List of States and Towns used for the study

$\begin{array}{cccc}\text { S/N } & \text { State } & \text { Urban } & \text { Rural } \\ 1 & \text { Abia } & \text { Umuahia } & \text { Isuochi } \\ 2 & \text { Anambra } & \text { Awka } & \text { Umunze } \\ 3 & \text { Imo } & \text { Okigwe } & \text { Akokwa }\end{array}$

The choice of these towns was informed by their typical urban and rural characteristics with reference to the parameters of the study.

\subsection{Population for the study}

The population for the study was made up of two categories namely clergy/marriage counselors and married couples (intact and non-intact families). The exact population size was not determined hence the choice of convenience sampling technique in constituting the study sample.

\subsection{Sample for the Study}

Informed by the infinite population, the study sample was chosen by convenience but efforts were made to ensure diversified and extended coverage of the area studied. A sample size of 100 respondents was drawn up made up of 50 clergy, 20 intact couples, 10 single parents (males), 20 single parents (females).

\subsection{Instrumentation}

A structured questionnaire designed and rated on a 4 - point scale, validated within face and content parameters was used for data collection. The instrument with a reliability coefficient of 0.87 on the Cronbach Alpha scale was deemed suitable enough for the study.

\subsection{Data Analysis}

Data generated for the study was were analyzed using descriptive statistics of frequency, mean and standard deviation, while the null hypotheses were subjected to t-test.

\section{Results}

Analysis of data yielded the following results as shown in the tables below :

Table 2: Percentage Composition of Categories of Respondents

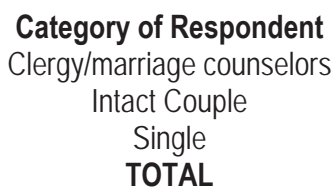

\begin{tabular}{cccccc}
\multicolumn{2}{c}{ Male (\%) } & \multicolumn{2}{c}{ Female (\%) } & \multicolumn{2}{c}{ Total (\%) } \\
25 & $(25)$ & 5 & $(5)$ & 30 & $(30)$ \\
20 & $(20)$ & 20 & $(20)$ & 40 & $(40)$ \\
10 & $(10)$ & 20 & $(20)$ & 30 & $(30)$ \\
55 & $(\mathbf{5 5})$ & $\mathbf{4 5}$ & $(\mathbf{4 5 )}$ & 100 & $(100)$
\end{tabular}

Source: Field survey 2014 
Research Question 1 What are the causes of marital conflicts in the Nigerian Society?

Table 3: Mean perception of respondents on Causes of marital crises

$\mathrm{N}=100$

$\begin{array}{cl}\text { S/N } & \text { ItemDescription } \\ 1 & \text { Social incompatibility of partners } \\ 2 & \text { Unrealizable ideals/standards } \\ 3 & \text { Sexual incompatibility } \\ 4 & \text { Infidelity/extra marital sexual affairs } \\ 5 & \text { Infatuations/fantasies } \\ 6 & \text { Lack of mutual respect } \\ 7 & \text { Poor moral character } \\ 8 & \text { Negligence/insensitivity to marital responsibilities } \\ 9 & \text { Poor marital communication } \\ 10 & \text { Absence/poor courtship } \\ 11 & \text { Egocentrism } \\ 12 & \text { Extreme sexual orientation } \\ 13 & \text { Third party syndrome } \\ 14 & \text { Gossip/nagging tendencies } \\ 15 & \text { Barenness } \\ 16 & \text { Desire for male children }\end{array}$

$\begin{array}{ccc}\mathbf{X} & \text { SD } & \text { Remark } \\ 2.59 & .79 & \text { Accept } \\ 2.89 & .56 & \text { Accept } \\ 2.87 & .61 & \text { Accept } \\ 3.00 & .76 & \text { Accept } \\ 2.56 & .68 & \text { Accept } \\ 3.15 & .76 & \text { Accept } \\ 3.23 & .66 & \text { Accept } \\ 3.05 & .51 & \text { Accept } \\ 2.69 & .45 & \text { Accept } \\ 3.02 & .67 & \text { Accept } \\ 2.87 & .67 & \text { Accept } \\ 3.14 & .59 & \text { Accept } \\ 3.50 & .41 & \text { Accept } \\ 2.90 & .34 & \text { Accept } \\ 3.33 & .55 & \text { Accept } \\ 2.92 & .68 & \text { Accept }\end{array}$

Source: Field survey 2014

Table 3 above shows that respondents accepted all the variables as causes of marital crises in the Nigerian society.

Research Question 2: What are the possible consequences of marital crises?

Table 4: Mean Perception of Respondents on possible consequences of marital crises

$\begin{array}{cl}\mathrm{N}=100 & \\ \mathbf{S} / \mathbf{N} & \text { Item Description } \\ 1 & \text { Loss of spousal confidence } \\ 2 & \text { Poor emotional health of spouse } \\ 3 & \text { Poor emotional health of children } \\ 4 & \text { Social insecurity } \\ 5 & \text { Economic insecurity } \\ 6 & \text { Negative mentoring for children } \\ 7 & \text { Poor physical health/nutritional status of children } \\ 8 & \text { Dissolution of marriage } \\ 9 & \text { Suicide tendencies } \\ 10 & \text { Threat to life of partner } \\ 11 & \text { High rates of juvenile challenges } \\ 12 & \text { Physical assaults } \\ 13 & \text { Escalation of social vices } \\ 14 & \text { Poor academic achievement by children }\end{array}$

$\begin{array}{ccc}\mathbf{X} & \text { SD } & \text { Remark } \\ 2.56 & .57 & \text { Accept } \\ 3.62 & .23 & \text { Accept } \\ 3.05 & .51 & \text { Accept } \\ 2.84 & .72 & \text { Accept } \\ 2.66 & .46 & \text { Accept } \\ 3.00 & .76 & \text { Accept } \\ 2.51 & .54 & \text { Accept } \\ 3.05 & .55 & \text { Accept } \\ 3.05 & .55 & \text { Accept } \\ 2.65 & .49 & \text { Accept } \\ 3.02 & .80 & \text { Accept } \\ 3.04 & .54 & \text { Accept } \\ 3.04 & .54 & \text { Accept } \\ 3.03 & .51 & \text { Accept }\end{array}$

Source: Field survey 2014

Table 4 above shows that respondents accepted all the variables as causes of marital crises in the Nigerian society.

Research Question 4: What strategies can be used in managing marital crises Effectively? 
Table 5: Mean Perception of Respondents on Strategies for Effective Management of Marital Crises

$\mathrm{N}=100$
$\mathbf{S} / \mathbf{N}$
1
2
3
4
5
6
7
8
9
10
11
12

Item Description
Marriage counseling
Guided courtship
Effective marriage social networking
Legislating against forced/early marriage
Introducing Pre-marriage courses in curriculum
Legislating against spousal abuse
De-emphasizing children in marital union
Regular seminars on marital issues
Regular renewal of marital vow
Defining position of in-laws early in marriage
Establishing common family purse/joint account
Putting spouse before children

$\begin{array}{ccc}\mathbf{X} & \text { SD } & \text { Remark } \\ 3.55 & .56 & \text { Accept } \\ 3.47 & .55 & \text { Accept } \\ 2.98 & .35 & \text { Accept } \\ 3.07 & .54 & \text { Accept } \\ 3.57 & .67 & \text { Accept } \\ 3.55 & .57 & \text { Accept } \\ 3.21 & .77 & \text { Accept } \\ 2.95 & .53 & \text { Accept } \\ 3.25 & .66 & \text { Accept } \\ 3.44 & .51 & \text { Accept } \\ 2.82 & .42 & \text { Accept } \\ 3.33 & .62 & \text { Accept }\end{array}$

Source: Field survey 2014

Table 5 above shows that respondents accepted all the variables as causes of marital crises in the Nigerian society.

Table 6: Result of ANOVA (One-way) Summary Ho: 1 "There is no significant mean opinion difference among the clergy/marriage counsellors, intact married couples (IMC) and Single Parents Families (SPF) on causes of marital crises"

$\begin{array}{lcccccc}\text { Source of Variation } & \text { SS } & \text { Df } & \text { MS } & \text { F-Crit } & \text { F-Ratio } & \text { Decision } \\ \text { Between Group } & 8.32 & 2 & 4.26 & 3.0 & 0.005^{*} & \text { Accept } \\ \text { Within Group } & 172263.08 & 97 & 874 & & & \\ \text { Total } & 172271.6 & 99 & 878.69 & & & \\ \text { *Not significant } \mathrm{P}=0.05 \mathrm{df}=2 \text { and } 97 & & & & & & \end{array}$

The above table shows that the F-ratio (.005) is less than calculated F-value (3.0) the hypothesis of no significant mean opinion difference is therefore accepted

Table 7: Result of t-Test applied on Null Hypothesis 2: Of no significant mean opinion difference between male and female respondents on causes of marital crises

$\begin{array}{lcccccccc}\text { Category of Respondent } & \mathrm{N} & \mathrm{X} & \mathrm{SD} & \mathrm{Df} & \mathrm{P} & \mathrm{t}-\text { Crit } & \mathrm{t} \text {-Cal } & \text { Decision } \\ \text { Male } & 55 & 3.25 & .46 & 98 & 0.05 & 1.96 & 1.04 & \text { Accet } \\ \quad \text { Female } & 45 & 3.57 & .49 & & & & & \\ \text { *Not Significant } \mathrm{P}=0.05 \mathrm{df}=98 & & & & & & & & \end{array}$

Since the calculated $t$ is less than the critical t-value at 0.05 alpha level and 98 degrees of freedom the hypothesis of no significant mean opinion difference is accepted.

Table 7: Result of ANOVA (One-way) Summary Ho: 3 "There is no significant mean opinion difference among the clergy/marriage counsellors, intact married couples (IMC) and Single Parents Families (SPF) on consequences of marital crises"

$\begin{array}{lcccccc}\text { Source of Variation } & \text { SS } & \text { Df } & \text { MS } & \text { F-Crit } & \text { F-Ratio } & \text { Decision } \\ \text { Between Group } & 8.36 & 2 & 4.29 & 3.0 & 0.015^{*} & \text { Accept } \\ \text { Within Group } & 172266.8 & 97 & 884 & & & \\ \text { Total } & 172275.16 & 99 & 888.29 & & & \\ \text { significant } \mathrm{P}=0.05 \mathrm{df}=2 \text { and } 97 & & & & & & \end{array}$

The above table shows that the F-ratio (.015) is less than calculated F-value (3.0) the hypothesis of no significant mean opinion difference is therefore accepted 
Table 8: Result of t-Test applied on Null Hypothesis 4: of no significant mean opinion difference between male and female respondents on consequences of marital crises

$\begin{array}{lcccccccc}\text { Category of Respondent } & \mathrm{N} & \mathrm{X} & \mathrm{SD} & \mathrm{Df} & \mathrm{P} & \mathrm{t}-\text { Crit } & \mathrm{t} \text {-Cal } & \text { Decision } \\ \text { Male } & 55 & 2.96 & 0.71 & 98 & 0.05 & 1.96 & 1.59 & \text { Accept } \\ \text { Female } & 40 & 2.89 & 0.54 & & & & & \end{array}$

Since the calculated $t$ is less than the critical t-value at 0.05 alpha level and 98 degrees of freedom the hypothesis of no significant mean opinion difference is accepted.

\section{Major Findings}

Consistent with the study objectives, research questions and analysis of data the following major findings were made:

Research Question 1 What are the causes of marital conflicts in the Nigerian Society?

The following were indicated as possible causes of marital crises in the Nigerian society;

Social incompatibility, sexual incompatibility, marital infidelity, infatuations, and poor marital communication.

Research Question 2: What are the possible consequences of marital crises?

Findings on possible consequences of marital crises include; loss of spousal confidence, emotional trauma on both couple and children, negative mentoring for children, poor physical, emotional and mental health, escalation of social vices and threats to life of partner.

Research Question 3: What strategies can be used in effectively managing marital crises?

The study indicated the following as possible strategies for managing marital crises; regular marriage counseling, seminars, conferences and workshops on healthy marital living, pre-marriage engagement courses and courtship, defining the place of in-laws in the family very early in the life of the marriage, placing less emphasis on children, sexual satisfaction etc.

Based on the results of hypothesis testing, all the null hypotheses stated for this study were accepted at the stated alpha level and observed degrees of freedom.

\section{Discussion}

Issues bordering on in-laws, friend, and relatives constitute a point that never seem to get out of style. Experience over years and across many cultures and clime has shown that mothers- in-law are notorious for many family crises. Couples should learn how to put in-laws, relatives and friend in their proper place, outside the sanity of their home. Wives always have a way of brewing or manufacturing non-existent problems that often are blown out of proportion while blaming and accusing their innocent husbands of complicity and/or indulgence (Okon, 2010). This is absolutely wrong, and there is need for a wife to undertake self assessment first (to know where she got it wrong) before transferring anger or aggression to the husband.

Third-party syndrome has rocked many homes in Nigeria as confirmed in this study to this effect, couples should not allow in-laws, relatives and friends to have negative influence on their marriage and as a rule dissociate from people that always find faults with your spouse. Many marriages have gone under due to lies manufactured and told one party by so-called friends and relatives. Couples should stay away from people that always want to be their private investigator. It is apt to state that we do not need to allow trust to find its way out of our homes just because someone that "cares" about your marriage more than we do told us something about our spouse.

It is estimated that $80 \%$ or more of the time marital crises are hinged on this all powerful issue of our normal life sex. It is either one party is not getting enough or there is distrust about it, or someone is not enjoying the sex sessions (mfwthoughtsabout-god.com). The above assertion supports part of the findings of this study that identified sex as one of causes of marital crises in the Nigerian society. It should be noted that your spouse cannot ask for too much sex, as long as he/she wants to, you should respond to it. It is possible to have a couple with different sexual desire level or orientation. Taking each other for granted in the area of sex is a major mistake married people often make. Nothing is more potent and distortive than sex in marriage. Omartian, (2001) rather advises that we be patient with our spouse and work on building a healthy sexual life together. A wife should always bear in mind that her man must be psychologically (emotionally) stable, and stress-free to complement her sexual life. This is a bitter truth and obviously one that injects weaknesses into marital relationship. 
Money is one area where marriages are tested today without exception. Whether you are rich or poor, educated or uneducated, you will have to deal with the financial demon that is out to break your home. From the man the refuses to work or that is finding it difficult to get a well paying job, to the wife that earns much more than the husband, to a spouse that won't cut coat according to pocket size, to a family carrying too much financial responsibilities from relatives and the ones that have poor financial planning skills. Men turn to crime to satisfy an insatiable wife financially. Couples go into rituals with their children as sacrifice just for a little more money. All there end up destroying the family more at the end (Awake, 2009).

In solving these problems a basic tenet here is that couples need to define their reality. We are not like "the so and so" but we can get there with time. Couples need to develop financial plans for their future and work towards it. Such plans must be reviewed from time to time as new challenges emerge. They should have a saving culture and in addition think of a small business to do that would guarantee a daily income would do wonders to the happiness experienced in the home (Awake, 2009).

That many families have suffered untold pains because of what could be referred to as "children factor". The study lays credence to this claim and further cautions that though children are a blessing to marital union between man and wife, greater emphasis on having children above the marriage itself places a heavy burden on the union. It is the union that produces the child, not the other way round. Sadly today, couples put children before marriage, some fellow would not even many the so called "love of their life" if she does not get pregnant first. This is the primary reason why childless couples seem not to have peace; they seem to fail to understand that children are not the primary reason for marriage. It common knowledge that Children will grow up and leave their parents alone to start their own families, but your spouse will stay (till death separates). Another variant to this is having children that are not planned for; or not of the desired sex. Having children without the financial or emotional strength to lake care of them is the primary reason "for poverty, sickness, high child and maternal mortality and irresponsible adult population.

Solving this problem has to start with a change of mind-set about children and marriage. A basic tenet here is to put your spouse at all times before your children (Templer,. 2008). Spouses (especially wives) who tend to see children as substitutes to their partners should retrace steps. Children should be made to understand and appreciate that your spouse is taking the first place and nothing less (savemymarriagetoda.com).

\section{Recommendations}

Based on the objectives and findings of the study, the following recommendations are made:

1. Family and healthy living with special reference to counseling for marital life should be emphasized in the curriculum especially at the secondary and post-secondary levels

2. Counselling centres should be established in urban and rural neighbourhoods.

3. Continuing education programmes on marriage and family living should be made integral component of regular schooling.

4. Regular workshops, seminars and conferences organized by stakeholders such as religious bodies, the government should be availed couples and prospective couples to enable them to acquire requisite skills and habit culture for successful marital life.

\section{Conclusion}

In this paper attempts have been made to underscore the various factors that are responsible for marital crisis in the Nigerian context. Consequences of marital crises were also examined in the context of making recommendations on strategies that can be used to reduce marital crises and make marriages a more pleasant experience.

\section{References}

Amadi U.P.N (2009): Gender Sensitivity Education and Sustainability of Africa's Dynamic Socials Values. A Paper Presented at a National Conference held at the Federal College of Education (Tech.) Umunze from $17^{\text {th }}-22^{\text {nd }}$ October.

Awake (2008): Marriages in Distress. How can you make your marriage a success? The Watch Tower Magazine (July edition). Pennsylvania: The Watch Tower and Tract Society.

Awake (2009): Secrets of Family Success. The Watch Tower Magazine (October edition). Pennsylvania: The Watch Tower and Tract Society,

Bowman (2010): Yahoo Contributor Network http://www.savemvmarriaqetoday.com/aticles/manaqement.downioaded21/11/2010)

Buckwell, P.J. (2010): Marital Crisis Resolution Coping with Adultery. New York: Cowling Investigation incorporation. 
Dee Haans, W (1986): Keys to a Happy Marriage http://www.thoughts-about-god.CQmdownloaded21/11/2010).

Diaman .S (2010): Handling Family Crisis, (http:www.savemymarriagetoday.com/articles/manag.downloaded21/11/2010).

Edger, D (1996): What will Make Marriage Work. Family Marital Relationships. In Sper, D (ed) Radio Bible Class. Michigan: Grand Rapids Incorporation.

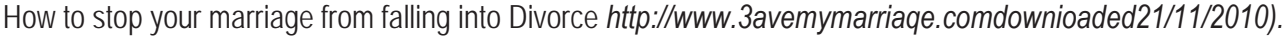

How to take care of financial management problem in your marriage (http:www.savemymarriage.comdownloaded21/11/2010).

Meyer C (2010): What is Midlife Crisis? (Bigstockphoto.com,downloaded 29/11/2010).

Okon, I.E(2010): How to make your Marriage Work :Daily Sun Newsaper (Tuesday, May 25p.19).

Omartian, S (1997): The Power of a Praying Wife. Eugene-Oregon: Harvest House Publishers.

Omartian, S (2010): The Power of a Praying Husband. Eugene-Oregon: Harvest House Publishers.

Onwuka, J.O (1997): Agents and Processes of Socialization in Traditional Nigeria. In Onwuka J.O \& Ahaiwe SC (eds). Nigerian Heritage. Owerri: Whytem Publishers Nig.

Templer, R. (2008): The Rules of Parenting London: Prentice Hall Pearson Education Ltd.

Tobin, M (2004): Marital Crisis; Time does not heal all wounds. New York: The United States Journal Proceedings of the National Academy of Sciences (PNAS).

Seun, 0. (2010): Marital Crisis and Divorce; The Reasons all Modern Remedies are Ineffective. http://www.savemvmarriagetoday.com /articles/manage.,downioaded29/1 1/2010).

Scobie, C.J. (2009): Defining the New Testament Logic on Divorce and Re-marriage in a Pluralistic Context. fhttp://www,savemvmarriagetoday.com/articfes/manage.downfoaded29/1 1/2010).

The Holy Bible New International Version (1984): Bangkok International Bible Society.

Watch Tower Bible and Tract Society of Pennsylvania (1996): Marital Covenants.

Wasson, N (2010): How to keep Hope Alive during a Marriage Crisis (http://www.savemvmarriage.com/articfes /rnanagemenldownloaded29/1 1/2010).

Weaver A (2009); What are the main causes of a marriage crisis? http;/www.premaritalonline.com downloaded29/1 1/2010).

Zhekwo, Y.K (2009): Defining the New Testament Logic on Divorce and Remarriage in a Pluralistic Context. London, Pickard Publications. 